\title{
Reframing language, disrupting aging: a corpus-assisted multimodal critical discourse study
}

\author{
Rosita Belinda Maglie and Laura Centonze
}

\begin{abstract}
Purpose - The purpose of this paper is to explore two channels of communication (i.e. texts and images) from a non-governmental organization website called \#DisruptAging with the aim of finding how multimodal knowledge dissemination contributes to dismantling misconceptions about the aging process.

Design/methodology/approach - This analysis is based on an integrated approach that combines corpus-assisted discourse analysis (cf. Semino and Short, 2004; Baker et al., 2008, Baker, 2010) and multimodal critical discourse analysis (Machin and Mayr, 2012) via the American Medical Association format (2007) and the suite of FrameWorks tools (2015, 2017), which are applied to the collection of texts and images taken from \#DisruptAging.

Findings - A total of 69 stories corresponding with 218 images of older adults have shown to be powerful textual and semiotic resources, designed both for educational and awareness-raising purposes, to promote the so-called "aging well discourse" (cf. Loos et al., 2017).

Social implications - This discursive approach to the textual and visual material found in \#DisruptAging hopes to influence the governing institutions that we construct, and the people who are given power to run them, with the goal of fostering fair treatment of older people within society.

Originality/value - There is a lack of studies investigating counter-discourse forms available online, which use textual and visual language to change the way society conceives the idea of aging.
\end{abstract}

Keywords Multimodal critical discourse analysis, American Medical Association manual of style, Corpus-assisted discourse studies, The frameworks toolkit, Visual ageism, \#DisruptAging

Paper type Research paper

\section{Visual ageism in the media}

The present paper deals with the issue of visual ageism in the media and, more specifically, it investigates "the social practice of visually under-representing older people or misrepresenting them in a prejudiced way" (Loos and Ivan, 2018, p. 164); in addition to this, the present study attempts to shed light on nonrealistic and over-homogenized characterizations of older adults cast in peripheral roles without positive attributes or depicted positively as being active, healthy and independent [1]. Such stereotyped descriptions have already represented the object of further analysis on the part of scholars who have identified patterns for the representation of the aging phenomenon from different perspectives. For instance, Levy and Banaji (2002) has identified self-perception of aging in older adults as a factor improving longevity and the quality of life: the more positive the selfperception of the aging process and of any age-related prejudiced vision, the better the quality of life for older people is; Loos (2018) analyses the perception of stock photos by older people and the extent to which they relate some of them to specific stages of their lives (e.g. pension, housing); the study also emphasizes how older people are represented in stock photos as "eternally youthful" (ivi, p. 369).
Rosita Belinda Maglie and Laura Centonze are both based at Department of Education, Psychology and Communication Sciences, University of Bari, Bari, Italy.
(C) Rosita Belinda Maglie and Laura Centonze. Published by Emerald Publishing Limited. This article is published under the Creative Commons Attribution (CC BY 4.0) licence. Anyone may reproduce, distribute, translate and create derivative works of this article (for both commercial and non-commercial purposes), subject to full attribution to the original publication and authors. The full terms of this licence may be seen at http://creativecommons.org/ licences/by/4.0/legalcode

Authors would like to express their very great appreciation to AARP (www.aarp.org) for allowing them to use and analyze multimodal contents from their website and, more specifically, those relating to the Disrupting Aging section. 
Notwithstanding this, for most aging groups the aging phenomenon is definitely not a flawless process; biased visions of the aging phenomenon can have a number of negative consequences both at a personal and interpersonal level. On the one hand, this can have a negative impact on self-esteem, health status, physical well-being and cognitive performance of older people; on the other, it inevitably determines the societal exclusion of the older-old, especially those who are no longer able to be embedded in the discourse of successful and active aging (Ylänne, 2012; Martin et al., 2015). Such biased (often negative) visions of the aging process can be implemented by the use of linguistic forms that have a negative connotation and can manipulate the minds and cognitive processes of aging, causing it to be stigmatized by the whole community. Bearing in mind the aforementioned consequences which such stereotyped visions can have, there is an urgent need to encourage the creation of "counter-discourse" forms using power and authority to empower younger generations and convince them of the need for a societal paradigm shift as regards aging.

To detect instances of "counter-discourse" or "aging well discourse" (cf. Loos et al., 2017) the study is based on an integrated approach that combines both a corpus-assisted discourse analysis (cf. Semino and Short, 2004; Baker et al., 2008; Baker, 2010) and a multimodal critical discourse analysis (Machin and Mayr, 2012) to a collection of narratives (i.e. texts and images) dealing with aging. Three main research questions are thus addressed:

$R Q 1$. Which are the dominant narrative patterns of thinking when it comes to aging?

$R Q 2$. How do these narratives shape and expand people's vision on ageism?

$R Q 3$. How can multimodal knowledge dissemination contribute to dismantling misconceptions about the aging process?

\section{Materials and methods}

Materials for this study are taken from the website \#DisruptAging [2] which is an American information service specifically designed by the AARP Real Possibilities [3] to have a new conversation about how we want to live and age, through various multimedia resources, i.e. stories, images, articles in newsletters, videos and also links to Social Network Sites (SNSs; e.g. Facebook and Twitter). This work focuses on a corpus of 69 stories and their related 218 attached images, published in the free Disrupt Aging Newsletter delivered twice per month from 2018 to 2019 (i.e. specifically all months in 2018 and the first three months in 2019). These inspirational stories accompanied by images are chosen as they represent a spotlight for extraordinary people - from celebrities to everyday citizens - who write and set their own faces against outdated beliefs about aging to spark new solutions for older people.

\subsection{Stories}

The stories ( $N=69$ ) are approached drawing on The American Medical Association (AMA) Manual of Style (2007) and on FrameWorks Tools (2015, 2017). The choice of these two reference tools is deliberate and in line with the aims of the present study: The AMA Manual of Style represents one of the most reliable sources in the field of medical publications and scientific writing where scholars can find answers to their most dubious issues, e.g. citing electronic references, ethical and legal issues in the medical domain, updates on fieldrelated terminology and, last but not least, the use of neutral (patient-friendly) terminology when describing pathologies and stages of human life, e.g. aging. The FrameWork Tools website promoted by the FrameWorks Institute represents a useful resource for changing the way people around the world deal with social issues such as aging, health, human rights, environmental problems and so forth. More specifically and as regards the focus of 
this study, i.e. (re)presenting aging, the FrameWork Tools identifies a set of cultural models among which are the following implicit assumptions:

A1. Ideal vs real: the public's general perception of the aging phenomenon is strongly related to its consideration as a process of deterioration, dependency, reduced potential, family dispersal and digital incompetence;

A2. Us vs them: an "Us vs. Them" perspective includes the consideration of older people as outcasts of society and inevitably encourages discriminatory attitudes toward them.

Other categories identified by the FrameWork Toolkit include Individualism, a feature characterizing most elderly people, in that it defines them as individuals who are able to make their own choices individually and to make responsible financial choices also in view of retirement; Inefficient Government, as most people, especially in America, think that their government does nothing to support elderly people or to bridge the gap between young and old/elderly people in general; Fatalism, a category according to which individuals are responsible for their actions and their welfare; Cognitive Holes, relating to the lack of understanding that as people grow old their attitudes, perceptions and needs change accordingly.

The present study takes The AMA Manual of Style (2007) as a point of reference for the linguistic analysis as it lists, among other things, a number of terms related to the aging process. Here follow some excerpts (1 and 2) taken from the manual:

1. age, aged, school-age, school-aged, teenage, teenaged. The adjectival form aged, not the noun age, should be used to designate a person's age. Similarly, school-aged and teenaged are preferred to school-age and teenage. However, a precise age or age range should be given whenever possible. [...] Note: In some expressions regarding age, it is redundant to add of age after the number of months or years, as it is implied in the adjectives younger and older (ivi, p. 384-385);

2. age. Discrimination based on age (young or old) is ageism. Because the term elderly connotes a stereotype, avoid using it as a noun. When referring to the entire population of elderly persons, use of the elderly may be appropriate (as in the impact of prescription drug costs on the elderly, for example). Otherwise, terms such as older persons, older people, elderly patients, geriatric patients, older adults, older patients, aging adults, persons 65 years and older, or the older population are preferred. Note: In studies that involve human beings, age should always be given specifically. Researchers in geriatrics may use defined terms for older age groups, e.g. young-old (usually defined as 60 or 65 to 70 or so years) and old-old (80 years and older). (ivi, p. 416).

As can be seen in the instances provided above, the contrast between age as a noun and aged as an adjective appears to be particularly relevant, as the latter is being considered as a less biased expression for the description of aging; in addition, the second example provides a definition of ageism as a prejudiced way of describing aging and suggests possible definitions for its adequate description, which include the use of the term elderly as well as age for scientific research.

As far as the linguistic analysis is concerned, a corpus-driven approach to the stories is adopted, by means of the use of WordSmith Tools version 7 (Scott, 2016) to extract all the age-related terminology spotted in The AMA Manual of Style to verify its frequency and see the extent to which its use across the analyzed stories of the AARP website respects the AMA style. Based on their frequency relative to other terms, wordlists were generated for the following items (elder*; old*, senior*, control, choice, age, ag*) to see their collocates across the corpus. 


\subsection{Images}

Unique images ( $N=197)$ occur 218 times across the newsletter stories. These images are investigated using the tools of analysis found in Kress and van Leeuwen (2006), Machin and Mayr (2012) and Ledin and Machin (2018) to run the multimodal critical discourse analysis and to analyze how meaning - in our case, the idea of aging - is communicated through visual language (Kress, 2010). The investigation uses the toolkit developed by the FrameWork Institute and is aimed at detecting whether the six narratives identified by the Institute studying the lexical and grammatical choices in language across both media and advocacy materials (2015) are also visually present in the set of images taken from \#DisruptAging. The six narratives, exemplifying the idea of aging across the American population, are illustrated in Table 1.

The visual analysis aims to identify these dominant narratives through a careful process of description of features and elements, alone and in combination, guided by the tools provided, to grasp what American people think of, because their ideas of older people derive and become inseparable from the images they produce and are accustomed to seeing around them.

\section{Analysis and results}

\subsection{Stories}

The linguistic analysis involved the creation of age-related wordlists. It drew on the list of terms in The AMA Manual of Style and the analysis of their collocates across the corpus of stories taken from \#DisruptAging. The FrameWork Toolkit along with its cultural models as explained within the same section are used to contextualize and interpret findings. A general analysis was first run for the most frequently occurring age-related items in the corpus. The table summarizes the frequency for age-related items in the corpus along with their ratio, which was obtained by dividing the number of age-related items found $(x)$ by the overall number of age-related instances (y) across the study corpus. The result was then multiplied by an arbitrary number (100) to make figures more suitable for the purposes of our study, i.e. $(x / y) \times 100$ (Table 2).

As one would expect, the most recurrent words in the corpus are represented by age and old/older, with respectively $\mathrm{N}=247$ and $\mathrm{N}=82 / 91$ items found; the ratio is useful to weigh results against the overall number of age-related items found in the corpus, and it is here that the gap in frequencies between the two terms becomes visible: age is proportionately much more frequent than old/older (43.1\% vs $14.31 \%$ and $15.88 \%$ ); makeup/make-up was found 46 times in the corpus (8.03\% ratio), immediately followed by skin (39 items, 6.81\%) and hearing (34 items found, 5.93\%). Space precludes discussing all the occurrences found in the corpus, so the focus is on the most recurrent ones. In particular, the collocates related to each search word help define the connotation that each of them has in the representation of aging, together with the fears and misconceptions it attracts. The difference in frequencies across the study corpus corresponds to different visions of

\section{Table 1 Overview of the six framework institute narratives}

The Throwaway Generation narrative

The Vibrant Senior and Independent Senior narratives

The Aging Worker narrative

The Demographic Crisis narrative

The Government Actions narrative
Description

It highlights elder abuse and discrimination

They present idealized representations of the aging process

It focuses on older people inside and outside of the labor market It focuses on the ways in which aging affects society It describes solutions and actions with special reference to aging ( $\mathrm{O}$ 'Neil and Haydon, 2015, p. 5) 
Table 2 Overview of age-related keywords in the study corpus

Age-related keyword(s)

Frequency

Frequency ratio (\%)

Age

Old

247

43.11

Older

Makeup, make-up

82

14.31

Skin

Hearing

Control

Controls

Senior

Seniors

Seniority

Choice

Choices

Elder

Elderly

Total

$\begin{array}{rl}91 & 15.88 \\ 46 & 8.03 \\ 39 & 6.81 \\ 34 & 5.93 \\ 11 & 1.92 \\ 1 & 0.17 \\ 8 & 1.4 \\ 2 & 0.35 \\ 1 & 0.17 \\ 2 & 0.35 \\ 4 & 0.70 \\ 2 & 0.35 \\ 3 & 0.52 \\ 573 & 100\end{array}$

the aging phenomenon, namely, age is found to be used to describe aging from a more scientific or statistical perspective, as in the examples (1-2) provided below:

1. That's the age when fertility starts to drop off, according to the American College of Obstetricians and Gynecologists

2. Based on evidence from over 40,000 job applications," wrote the National Bureau of Economic Research, "we find robust evidence of age discrimination in hiring against older women, especially those near retirement age.

On the contrary, old appears to be more related to the social dimension of the aging phenomenon, as the two examples (3 - 4) below illustrate:

\section{I am aging, but I refuse to grow old}

4. It's not an "old person problem." Seniors sometimes get incontinence, but age is not the only cause. Incontinence can develop from a wide array of things

It is also interesting to note the contrast in Example (3) between age and old, as a way to contrast the scientific and physiological growth of a person with the social dimension of individual integration. Also makeup/make-up, skin and hearing suggest some stigmatized visions of the aging phenomenon with all its related problems. Makeup/make-up, which is found 46 times in the corpus, appears to be mainly related to one of the main issues one inevitably has to face in the aging process: makeup as a way for hiding age, wrinkles and, more generally, imperfections; makeup is also described in its chemical components and experiments for improving its quality (examples $5-9$ ):

5. As she launches her first line, she talks about race, Instagram, her best friend Edward Eninful (the new editor of Vogue) and the influence of her makeup-obsessed mother Jean

6. "You couldn't get anyone more makeup addicted than me"

7. She always put on a full face of makeup then got in the bath to get that dewy finish"

8. There was no makeup for women of color," she reminds me. NOTHING.

9. The dominant makeup look was matte and flat textured, created with products that had insufficient pigment for darker skins, which gave skin a sculpted and almost lifelike quality. 
Skin ( $N=39)$ is also interesting as a term for referring to the aging phenomenon; it is generally associated to color and tone, which become reference factors determining the aging effects as well as crucial points for contrasting the effects of aging (examples 10 - 14):

10. I was working all the time with pigments to make sure they work on all skin tones, particularly to make sure dark skin doesn't become ashy, pigments that are so rich they work on everybody.

11. A lot of time when you buy a normal shadow, it doesn't always work on every skin tone - it's chalky or too light.

12. A holographic eye gloss. Almost neon blue shadow, a balm stick and nude pigment for achieving McGrath's signature "hyper-real skin."

13. She's a 70-year-old woman who just wants to feel comfortable in her own skin.

14. Jean encourages McGrath to be creative with makeup, mixing pigments from scratch to get exactly the right color, adding heat to the skin with her fingertips to give it a healthier glow and soften the look of foundation.

The use of the word hearing $(\mathrm{N}=34)$ is dual across the corpus and emphasizes once again the degree of discomfort that aging people encounter. The examples below $(15-19)$ represent the main collocates for hearing:

15. Your ears are located next to the joint connecting your jawbone to your skull, and all that clenching and grinding can be linked to hearing loss or even cardiovascular problems, according to a Greek study.

16. Grinding your teeth may seem a harmless habit, bit according to body educator Yamuna Zake, it can lead to hearing loss.

17. So the hearing aids on view here, like the one designed by Elana Langer, are "bedazzled and bejeweled" with Swarovski crystals or metal, or metal minimalist.

18. An older person may be happy with their hearing aid as it

19. Could we get a vaccine to protect hearing loss along with our shot for small pox? Now that would be music for our ears!

The main collocate of hearing is loss $(N=17)$, a more neutral form hearing $(N=9)$, followed by hearing aids $(N=8)$. The contrast between hearing loss (examples 15, 16 and 19) and hearing aids (examples 17 and 18) speaks volumes about the attitude toward problems that affect many aging people: hearing impairment. To sum up, the common denominator of all the examples provided above represents the stereotype of the aging phenomenon as a process which negatively affects the individual.

\subsection{Images}

Most images $(\mathrm{N}=197)$ are color illustrations $(86.07 \%)$ with a standard orientation, shape and format (i.e. horizontal-rectangular in JPEG) and less than half of these images are DualPose Frame (30.50\%). Focusing on the subjects portrayed, images retrieved from the website include portraits of humans, close-ups of body parts, everyday objects and tools, as well as natural elements. However, there is a predominance of photographs of people (individuals vs groups, especially couples/families) (>50\%) portrayed in domestic/public or de-contextualized settings (e.g. colored background). In the images, participants are rarely looking at the viewer directly (51\%), resulting in a lack of the actor's demanding gaze (i.e. "offer" images). There is also a relatively high frequency of emotional processes (23.88\%) because most of them are pose photos, in addition to the presence of salient elements, as well as visual connections between features and Gestalt properties. 
In the following sections, each group of images is approached from both its literal (i.e. denotative) and suggestive (i.e. connotative) meanings that highlight and describe biological and cultural factors, either affecting or challenging the ageist beliefs around us. When objects, graphs and individuals are depicted in images, narratives suggested by FrameWorks Institute are identified and described, making reference to how actions (e.g. motion and pose) as well as transactions (e.g. verbal and non-verbal processes) are represented.

3.2.1 Drawings. Drawings $(N=8)$ develop mainly two of the dominant narratives: The Throwaway and The Aging Worker Narratives. The former is based on the negative treatment experienced by older people while the latter narrative tells us that older adults can be taken out of the labor market. Starting from the first narrative, the two drawings depict old mothers who become the target of maltreatment by their children. Both mothers and their children are portrayed standing in a line and next to one another. However, in Figure 1(a) they are back-to-back to represent the conflict, on the one hand, but touching each other to represent blood relationship, on the other. When focusing on the old woman, both the wavy line along her face standing for her hair and the teardrop running down her cheek - both rendered with the same color (i.e. white) - exemplify the old mother's deep sadness. Figure 1 (b) shows a son giving his back to his mother who passively watches him being about to fly far away from her.

Going on with the second narrative, the presence of the big hand that is about to flick the small man off of his office chair in Figure 2(a) and the presence of an old employee who has been just gone down in Figure 2(b) make us think that both drawings deal with retirement issues. The contrast between big vs small objects in the former image represents the concentration of power exclusively in the hands of the labor market exercised at the expense of the old individual employee. In addition, the innumerable heads represented by

\section{Figure 1 Throwaway narrative}

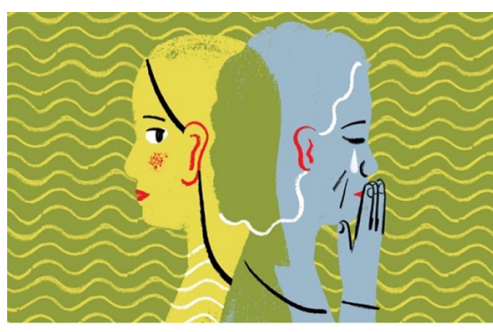

(a)

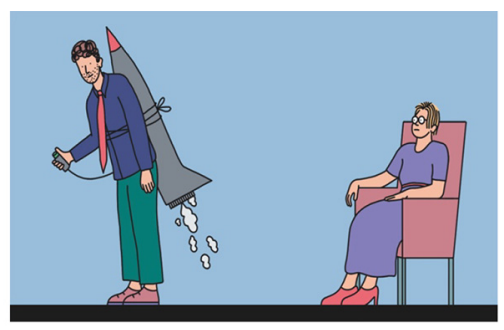

(b)

\section{Figure 2 Aging worker narrative}

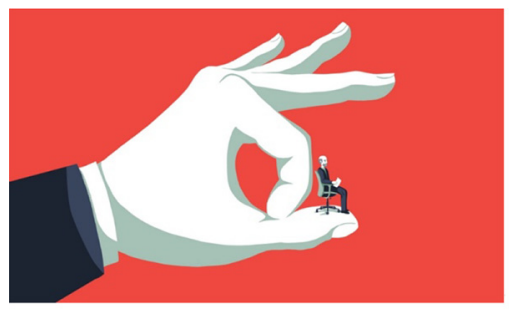

(a)

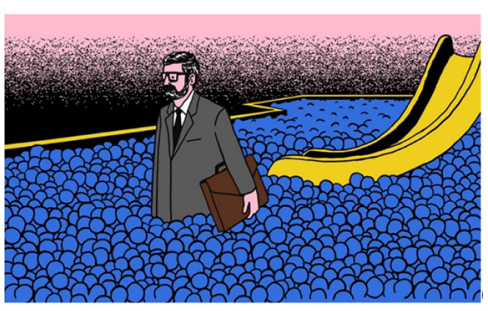

(b) 
the same color suggest a quicksand into which retired people are doomed to sink into so that they lose distinguishable human characteristic and dignity.

3.2.2 Photos: individuals and groups. When photos depict individuals $(N=60)$ and groups ( $N=36$ of which 19 show family and couple members and 18 show groups of people), they produce similar dominant narratives: the Vibrant Senior and the Independent Senior Narratives. Both dominant narratives center on a single definition of successful aging - the maintenance of physical activity, in the vibrant senior narrative [Figure 3(a)-3(b)], and the maintenance of mental acuity regarding the Independent Senior narrative [Figure 4(a)-4(b)]. In fact, images feature seniors remaining physically and socially active, thereby arguing that older adults can only continue to live independently to the extent that their physical and cognitive abilities remain strong.

In particular when families are represented, the Intergenerational Community Centers program proposed by the FrameWork Institute is one of the possible solutions to help people think differently about how to more fully incorporate older people into our communities (Sweetland, Volmert and O'Neil, 2017). This solution is shown in Figure 5(a)-5(b), and what we see are older people building relationships with young children, which enhances their mutual wellbeing; in so doing, these programs enable older people to assume new roles in their communities.

3.2.3 Photos: objects and graphs. Objects in photos $(N=7)$ and graphs $(N=3)$ construct the dominant Narrative of the Demographic Crisis. Both the map of the USA above with different colored pushpins placed to show cities with a high rate of survival and statistical graphs showing the mortality rate over time, convey a sense of urgency about aging issues. They show the impending social crisis due to the greying of the American population [Figure 6(a), 6(b) and 6(c)].

\section{Figure 3 Vibrant senior narrative}

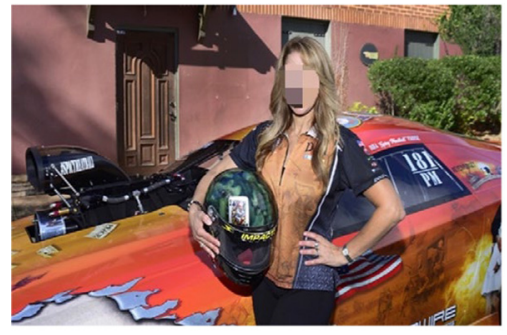

(a)

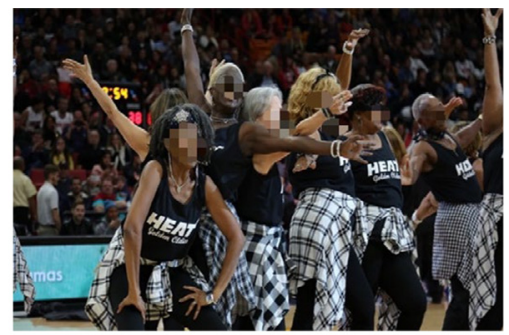

(b)

Figure 4 Independent senior narrative

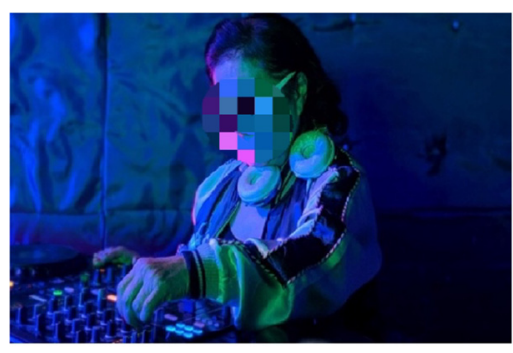

(a)

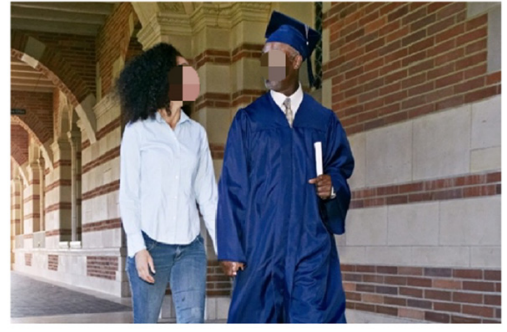

(b) 


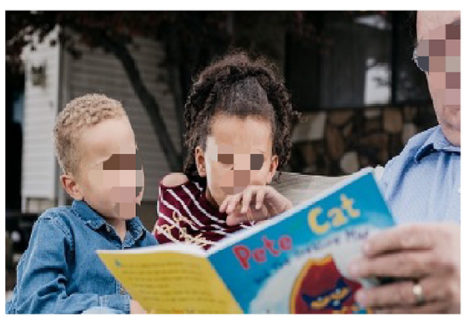

(a)

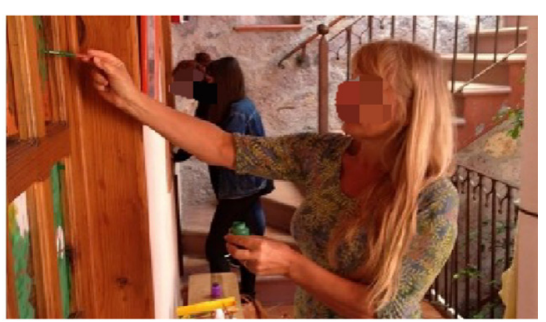

(b)

3.2.4 Photos: close-up of body parts. Close-ups of body parts $(N=18)$ tell another story which has not been identified by the FrameWork Institute. These are used to deal with taboo subjects, which cultural or religious custom usually does not allow people talk openly about, i.e. hearing problems [Figure 7(a)], sexual activity of the elderly [Figure 7(b)], incontinence or prostate problems for older men [Figure 7(c)] and facial hair for older women [Figure $7(d)]$. The choice of not using full-length portraits suggests that the website wants to handle these issues with great sensitivity and delicacy so that nobody is offended.

3.2.5 Double frame photos. However, double frame photos $(N=60)$ relate to change with age in the context of life continuities and life changes. Specifically, they relate both to sociocultural change, (i.e. the period effect in Bytheway's words) and the biological change,

\section{Figure 6 Narrative of the demographic crisis}

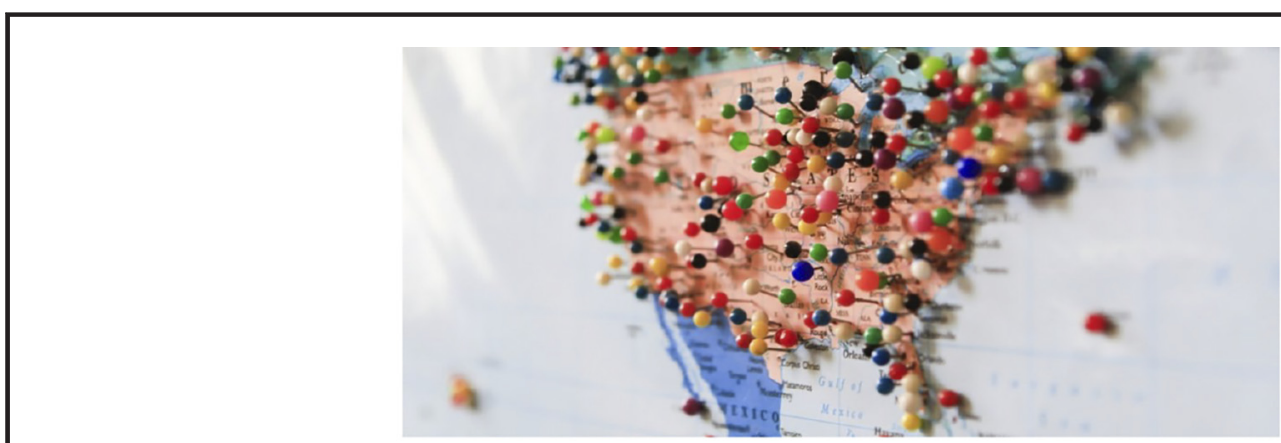

(a)

A Life expectancy by income quartile by year

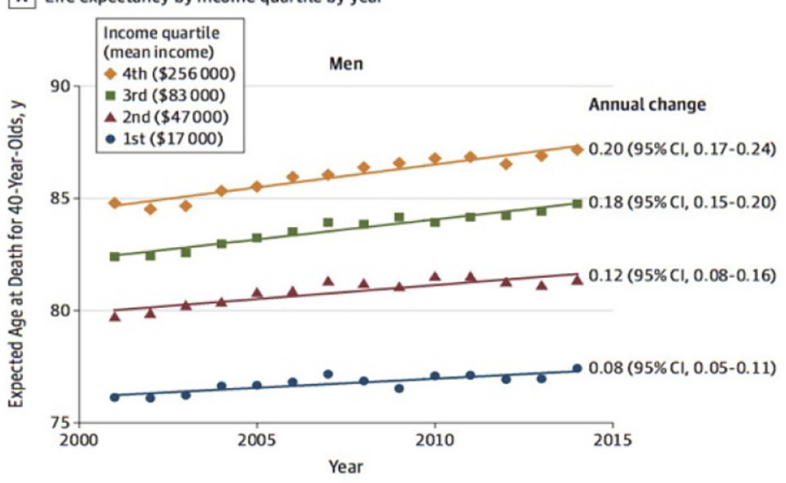

(b)

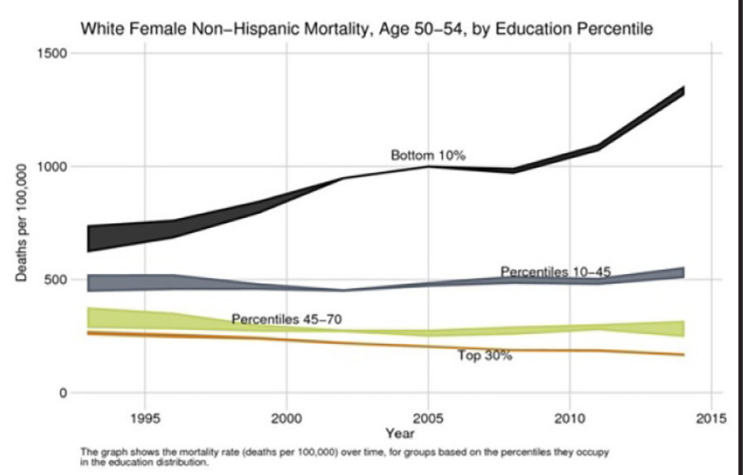

(c) 


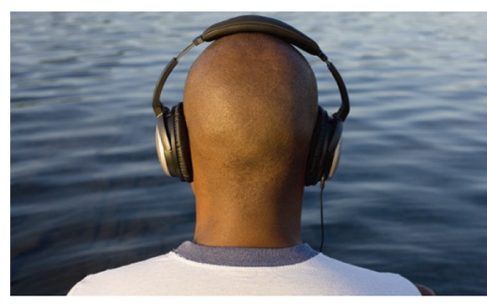

(a)

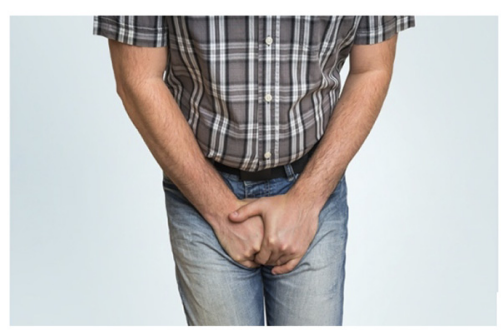

(c)

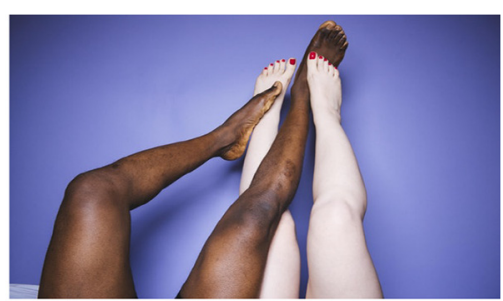

(b)

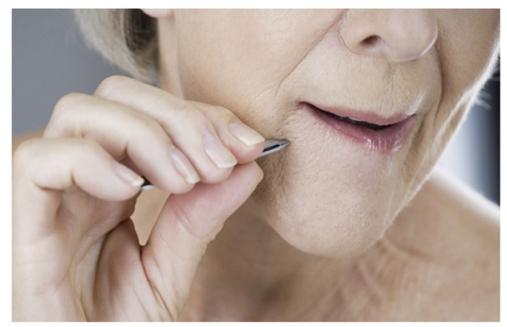

(d)

(i.e. the "age" effect in Bytheway's words [2012]). How change impacts the aging individual is another aspect that has not emerged in the FrameWorks Institute's publications (2015-2017). They feature the inevitability of change by tracking the changing generational structure of job conditions [Figure 8(a)] and marriage ceremonies [Figure 8(b)] regarding sociocultural change and the bodily changes of older women and men [Figures $8(\mathrm{c})$ and $8(d)]$.

\section{Figure 8 Narrative of the sociocultural and biological change}

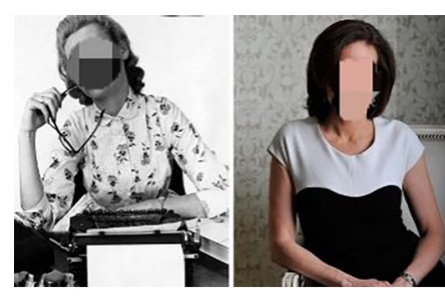

(a)

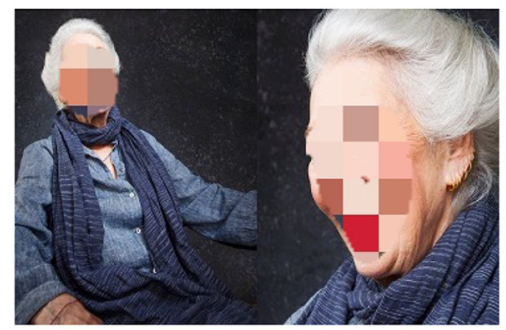

(c)

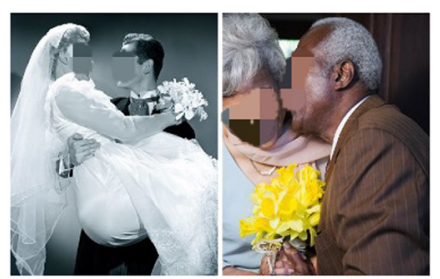

(b)

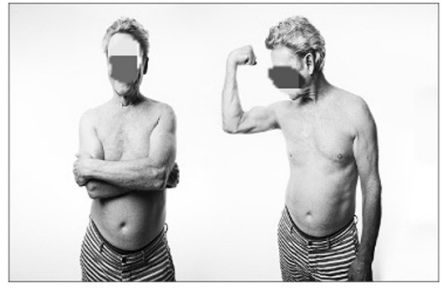

(d) 


\section{Discussion and conclusion}

We can identify how two predominant cultural models suggested by the FrameWorks approach across the corpus of stories are illustrated. In Ideal vs Real model, aging is socially represented as deterioration of the individual and, with reference to the corpus, this becomes more visible in either external properties of the individual (e.g. skin, makeup) or in socially related features like hearing. The Us vs Them cultural model encourages the marginalization of adult people and considers old people as society's outcasts: this becomes visible in the old-age dichotomy.

A discursive approach to the \#DisruptAging visual material shows that photos portraying individuals and groups of people (The Vibrant Senior Narrative/Independent Senior Narrative) clash with those portraying body parts and drawings (The Throwaway Narrative/The Aging Worker Narrative). However, both fail to mention that (in)dependence is not a matter of choice, and how governmental action (i.e. social policies and supports) might be necessary for an independence ideal to become a reality for many older adults. In particular, photos portraying groups (with peers and children) break down the Us vs Them thinking and offer concrete examples on which to build momentum as a society by taking advantage of people's contributions throughout life (Intergenerational Community Centers). Double frame photos feature the inevitability of sociocultural/biological change (Coupland, 2009) negotiated at the intersection of private and public domain - self- and other-positioning (Harrè, 1983). However, changes in women's body appearance can be discursively interpreted as women are not supposed to resist change, thus protecting the symbolic capital invested in bodily appearance and taking steps to avoid the ravages of time. Drawings and objects/maps are different from photos because they do not represent an example of "reality interrupted" (Sontag, 2004) but they are similar to photos as they are meant to represent more complex events (Ledin and Machin, 2018, p. 42): drawings represent the issue of maltreatment experienced by old people both at home and at work and objects/maps represent clearly and scientifically the growth of the grey population in America.

A discursive approach to the \#DisruptAging textual and visual material shows that texts, images and graphic elements presented by the AARP Real Possibilities outreach are powerful semiotic resources designed both for educational and awareness-raising purposes, aimed at changing the conversation about what it means to grow older. If this type of "aging well discourse" (cf. Loos et al., 2017), as promoted by \#DisruptAging, can be accepted by society, we could hope that this would change the institution we construct and the people who are given power to run it, for fair treatment of older people within society.

\section{Notes}

1. Although this research was jointly conducted by both authors, Rosita Belinda Maglie is responsible for sections 2, 2.2, 3.2, 3.2.1-5 and 4, whereas Laura Centonze for sections 1, 2.1 and 3.1.

2. Further information is available at the following pages: www.aarp.org/disrupt-aging/ and https:// www.youtube.com/hashtag/disruptaging

3. AARP is a non-profit, non-partisan organization that empowers people to choose how they live as they age.

\section{References}

American Medical Association (2007), "Manual of style committee", AMA Manual of Style: A Style Guide for Authors and Editors, 10th ed., Oxford University Press, New York, NY.

Baker, P. (2010), Sociolinguistics and Corpus Linguistics, Edinburgh University Press, Edinburgh.

Baker, P., Gabrielatos, C., Khosravinik, M., Krzyzanowski, M., McEnery, T. and Wodak, R. (2008), "A useful methodological synergy? Combining critical discourse analysis and corpus linguistics to examine discourses of refugees and asylum seekers in the UK press", Discourse \& Society, Vol. 19 No. 3, pp. 273-306. 
Coupland, J. (2009), "Discourse, identity and change in mid-to-late life: interdisciplinary perspectives on language and aging", Aging and Society, Vol. 29 No. 6, pp. 849-861.

Harrè, R. (1983), Personal Being, Basil Blackwell, Oxford.

Kress, G.R. and van Leeuwen, T. (2006), Reading Images: The Grammar of Visual Design, 2nd ed., Routledge, London.

Kress, G. (2010), Multimodality: A Social Semiotic Approach to Contemporary Communication, Routledge, London.

Ledin, P. and Machin, D. (2018), Doing Visual Analysis: From Theory to Practice, SAGE Publications.

Levy, B.R. and Banaji, M.R. (2002), "Implicit ageism", in Nelson, T. (Ed.), Ageism: Stereotypes and Prejudice against Older Persons, MIT Press, Cambridge, pp. 49-75.

Loos, E.F. (2018), "The organisational use of online stock photos. The impact of representing senior citizens as eternally youthful", Human Technology, Vol. 14, pp. 366-381.

Loos, E.F. and Ivan, L. (2018), "Visual ageism in the media", in Ayalon L. and Tesch-Roemer, C. (Eds), Contemporary Aspects on Ageism, Springer, Berlin, pp. 163-176.

Loos, E., Sourbati, M., Ivan, L. and Ekstrom, M.C. (2017), "Aging well? A cross-country analysis of the way older people are visually represented on websites of organisations for older people", Journal of Comparative Research in Anthropology and Sociology, Vol. 8 No. 2, pp. 63-83.

Machin, D. and Mayr, A. (2012), How to Do Critical Discourse Analysis: A Multimodal Introduction, SAGE Publications, London.

Martin, P., Kelly, N., Kahana, B., Kahana, E., Willcox, B.J., Willcox, D.C. and Poon, L.W. (2015), "Defining successful aging: a tangible or elusive concept?", The Gerontologist, Vol. 55 No. 1, pp. 14-25, available at: www.ncbi.nlm.nih.gov/pubmed/2484091610.1093/geront/gnu044

O'Neil, M. and Haydon, A. (2015), Aging, Agency, and Attribution of Responsibility: Shifting Public Discourse about Older Adults, FrameWorks Institute, Washington, DC

Scott, M. (2016), Wordsmith Tools version 7, Lexical Analysis Software, Stroud.

Semino, E. and Short, M. (2004), "Corpus stylistics: speech", Writing and Thought Presentation in a Corpus of English Writing, Routledge, London.

Sontag, S. (2004), Regarding the Pain of Others, Penguin, London.

Sweetland, J., Volmert, A. and O'Neil, M. (2017), Finding the Frame: An Empirical Approach to Reframing Aging and Ageism, FrameWorks Institute, Washington, DC.

Ylänne, D.V. (Ed.) (2012), Representing Aging: Images and Identities, Palgrave Macmillan, London.

\section{Further reading}

Bytheway, B. (2009), "Writing about age, birthdays and the passage of time", Aging \& Society, Vol. 29 No. 6, pp. 951-975.

Disrupting Aging website (2021), available at: www. aarp.org/disrupt-aging (accessed 1 November 2019).

Frameworks (2021), "Gaining momentum: a FrameWorks communications toolkit", [on-line], available at: www.frameworksinstitute.org/toolkit/gaining-momentum/ (accessed 8 April 2017).

\section{Corresponding author}

Rosita Belinda Maglie can be contacted at: rosita.maglie@uniba.it

For instructions on how to order reprints of this article, please visit our website: www.emeraldgrouppublishing.com/licensing/reprints.htm

Or contact us for further details: permissions@emeraldinsight.com 